\title{
A FORMAÇÃO CONTINUADA DE PROFESSORES DA EDUCAÇÃO BÁSICA MEDIADA PELAS TECNOLOGIAS DA INFORMAÇÃO E COMUNICAÇÃO
}

\author{
Marcia Leandro Benedet ${ }^{1}$ \\ Vanderleia Benedet Réus ${ }^{2}$ \\ Giovani Mendonça Lunardi ${ }^{3}$
}

\section{Resumo}

Este artigo descreve uma experiência em formação continuada mediada pelas tecnologias da informação e comunicação, tendo como público alvo 40 professores da Educação Básica de um município do sul de Santa Catarina. Como questão: qual o impacto da formação continuada em tecnologias educacionais no cotidiano dos professores? Desenvolveu-se uma pesquisa de natureza aplicada, com intuito de produzir conhecimentos por meio das vivências práticas sobre o uso das tecnologias da informação e comunicação. Foi relevante a discussão ao longo da formação em como mediar a aprendizagem desde a educação infantil até as séries finais do Ensino Fundamental com o uso das tecnologias. Os resultados evidenciaram a necessidade de formação continuada em tecnologias educacionais e sua articulação com as práticas pedagógicas, no sentido de otimizarem uma aprendizagem significativa.

Palavras-chave: Formação continuada. Tecnologias. Educação Básica.

\section{THE CONTINUED TRAINING OF TEACHERS OF BASIC EDUCATION MEASURED BY INFORMATION AND COMMUNICATION TECHNOLOGIES}

\begin{abstract}
This article describes an experience in continuing education mediated by information and communication technologies, targeting 40 primary school teachers from a municipality in the south of Santa Catarina. As a question: what is the impact of continuing education on educational technologies in teachers' daily lives? A research of an applied nature was developed, aiming to produce knowledge through practical experiences on the use of information and communication technologies. It was relevant the discussion throughout the training in how to mediate the learning from the infantile education until the final series of the Elementary School with the use of the technologies. The results evidenced the need for continuing education in educational technologies and their articulation with pedagogical practices, in order to optimize meaningful learning.
\end{abstract}

Key words: Continuing Education. Technologies .Basic Education.

\footnotetext{
${ }^{1}$ Mestranda Tecnologias da Informação e Comunicação -Universidade Federal de Santa Catarina(UFSC); Araranguá- Brasil. marciapro11@hotmail.com

2 Mestranda Tecnologias da Informação e Comunicação - Universidade Federal de Santa Catarina (UFSC); Araranguá- Brasil. leiareus@gmail.com

${ }^{3}$ Doutor em Filosofia - Universidade Federal do Rio Grande do Sul (UFRGS); Professor da Universidade Federal de Santa Catarina (UFSC).giovani.lunardi@ufsc.br
}

Criar Educação, Criciúma, v. 8, no1, jan/jul 2019.- PPGE - UNESC 


\title{
1. INTRODUÇÃO
}

A utilização das Tecnologias da Informação e Comunicação (TICs) em todos os espaços da sociedade oportunizou as mais diversas possibilidades de conexão e transformou radicalmente a forma como nos apropriamos do conhecimento.

De acordo com Behar e Col (2009, p. 20), em relação à educação, essas mudanças ocorreram de fora pra dentro. A sociedade se modificou tecnologicamente, posteriormente as tecnologias foram introduzidas na escola, esperando "um novo perfil de instituição e a reformulação dos atores envolvidos, entre eles, gestores da educação, professores, monitores e alunos".

Esse panorama atual requer um novo perfil de educador, um profissional competente que deve estar sempre atualizado fazendo uso das ferramentas tecnológicas em ações didáticas.

Na visão de Barragán (2017, p. 37),

\begin{abstract}
As características que definem o conhecimento hoje, bem como as novas formas de relacionamento entre as pessoas e, principalmente, a expansão da aprendizagem permitida pelas mídias digitais e internet, nos permitem rever as possíveis respostas que atualmente damos para as questões como: O que aprendemos? Como aprendemos? Onde aprendemos? Com quem aprendemos?
\end{abstract}

$\mathrm{Na}$ era da informação e da comunicação, a formação continuada permite a reflexão sobre o que é aprender e o que é ensinar no século XXI, bem como a urgência em buscar novas metodologias.

Assim, a formação continuada visa encontrar alternativas para o uso eficiente das tecnologias em sala de aula, promove reflexões acerca das inovações tecnológicas como facilitadoras do processo de ensinoaprendizagem, assim como fomentar o desenvolvimento de habilidades e competências digitais. Faz-se necessária a formação de professores em TICs aplicadas à educação, pois este tema ainda é percebido como tabu por muitos educadores, que se sentem inseguros e veem a tecnologia com desconfiança.

O Horizon Report (NEW MEDIA CONSORTIUM, 2015, p. 24) destaca:

Para preparar os alunos para um mundo que utiliza cada vez mais tecnologia, atuais e futuros educadores precisam aprimorar 
continuamente suas habilidades em face de orçamentos reduzidos. A falta de educação adequada ao professor, relativas a competências digitais, é um desafio que está amplamente documentado.

Dada a relevância da formação continuada com professores da Educação Básica, o presente estudo relata uma experiência de formação continuada ao longo de três meses, com 40 professores da Educação Infantil e Ensino Fundamental na cidade de Morro da Fumaça, SC. Além das reflexões sobre a necessidade de inovar, nesse espaço de tempo pôde-se conhecer os usos da TICs em sala de aula, os conceitos que norteiam esta temática e criar projetos interdisciplinares inovadores. Este artigo está estruturado em cinco sessões: introdução, fundamentação teórica, métodos, resultados e considerações finais, seguidas das referências.

\title{
2. A INTEGRAÇÃO DAS TECNOLOGIAS NA PRÁTICA PEDAGÓGICA
}

Ao longo de uma década, trabalhamos com formação continuada, interagindo com professores da Educação Básica que, dentre outros temas, chamam a atenção para discutir as tecnologias na educação. Há um sentimento de inquietação em relação a estes conceitos e usos.

Nesse sentido, SOUSA; MOITA e CARVALHO (2011, p. 24) enfatizam:

\begin{abstract}
A rapidez das inovações tecnológicas nem sempre corresponde à capacitação dos professores para a sua utilização e aplicação, o que muitas vezes resulta no uso inadequado ou na falta de criação diante dos recursos tecnológicos disponíveis. Mas não tendo mais 0 monopólio da transmissão de conhecimentos, exige-se à escola e ao professor, em particular, a função social de orientar os percursos individuais no saber e contribuir para o desenvolvimento de competências, habilidades e cidadania.
\end{abstract}

Faz-se necessário estudar novas teorias, rever metodologias, redesenhar um novo agir pedagógico frente as inovações tecnológicas deste século.

Considerando que nossos estudantes da Educação Básica são "nativos digitais" e necessitam de novas formas de aprender, há uma necessidade urgente de inovação no ensino. Aproximar as aulas do contexto social em que o aluno está inserido é prioridade, de modo que a tecnologia permeie as aulas de forma significativa, inclusiva e abrangente. 
É essencial que o professor se aproprie de gama de saberes advindos com a presença das tecnologias digitais da informação e da comunicação para que estes possam ser sistematizados em sua prática pedagógica. A aplicação e mediação que o docente faz em sua prática pedagógica do computador e das ferramentas multimídia em sala de aula, depende, em parte, de como ele entende esse processo de transformação e de como ele se sente em relação a isso, se ele vê todo esse processo como algo benéfico, que pode ser favorável ao seu trabalho, ou se ele se sente ameaçado e acuado por essas mudanças.

Tendo consciência que o universo de estudo é vasto quando falamos em TICs, o espaço da formação continuada torna-se indispensável para apresentar as referências de que os educadores devem se apropriar. Refletir sobre novas ideias, teorias e práticas que estão a nossa disposição para estudá-las, conhecê-las, e então fazer uma releitura e recriá-las. Um extenso número de projetos de aprendizagem mostra que as tecnologias da informação e comunicação são excelentes para otimizar a aprendizagem dos estudantes.

Para Molin e Raabe (2012, p. 250),

[...] muito se tem discutido sobre a necessidade de o professor frequentar cursos de formação continuada, como forma de assegurar o desenvolvimento de competências que o habilitem a inserir, criativa e criticamente, os novos recursos na prática pedagógica, a atualizar os conhecimentos iniciais e a avaliar, no contexto atual, as mudanças necessárias para inovar essas práticas, atendendo às reais necessidades e interesses da nova geração.

Dos educadores deste século, espera-se um comportamento mais interativo, permeado por tecnologias digitais de informação e comunicação. Nesse sentido, a formação continuada permite a apropriação do conhecimento científico por parte dos educadores participantes. Propicia a reflexão acerca da inovação das aulas a partir do uso das TICs, aproximando-as dos conteúdos escolares no sentido de otimizar a prática com 0 apoio dos referenciais teóricos.

Dedicar-se ao estudo das tecnologias educacionais permite ao professor rever seus conceitos de aula tradicional. Integraras tecnologias, sem perder 0 foco no currículo.

Nesse sentido, argumenta Costa et al (2012, p. 94)

Porém, no caso específico da formação de professores para a integração das tecnologias, o domínio da técnica não pode estar dissociado do domínio do conteúdo disciplinar e da prática 
pedagógica. Se, por um lado, o professor precisa de dominar os conteúdos da sua área disciplinar, por outro, é a sua competência pedagógica que o torna um bom profissional da educação. São estes dois domínios que, quando devidamente articulados, constituem o saber específico do professor e o distinguem de um pedagogo ou de um especialista da área.

Ao desenvolver a formação continuada em TICs, alguns conceitos foram essenciais aos educadores, no sentido de ampliar o conhecimento sobre o tema, como demonstra a figura 01.

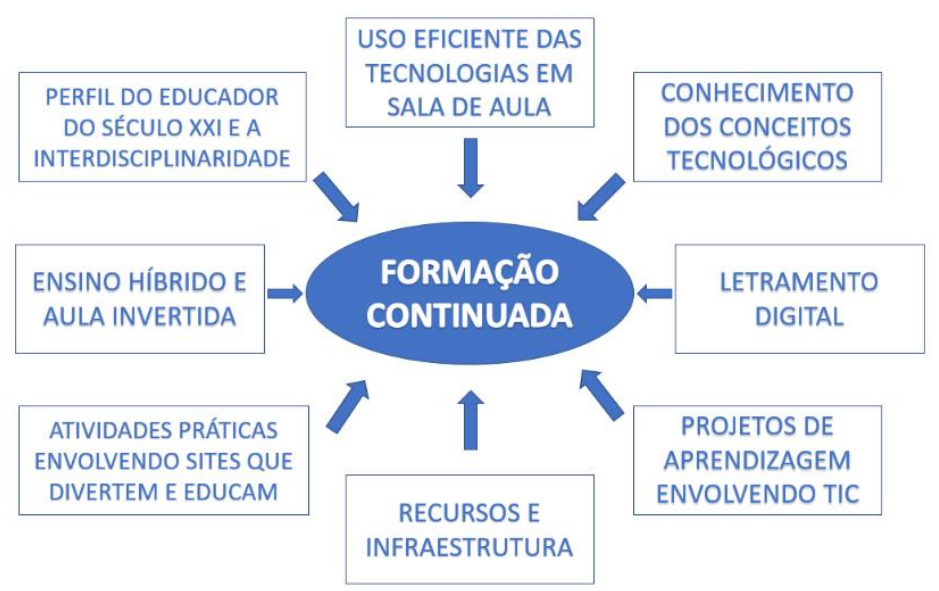

Figura 01: Estrutura dos conhecimentos estudados na formação continuada.

Fonte: Benedet, Reus e Mendonça.

De acordo com Ferrari e Sotero (2017, p. 78),

Conforme surgem novas tecnologias, nascem também novas formas de aprender e assim novas competências são exigidas, novas formas de se realizar 0 trabalho pedagógico são necessárias $e$, fundamentalmente, é necessário formar continuamente o novo professor para atuar neste ambiente do processo de ensinoaprendizagem.

A formação continuada propicia a inovação e permite ao educador se apropriar de novos conceitos referentes às TICs e adentrar a estas novas práticas pedagógicas. O professor há de se reinventar, num processo dialético de compreensão, reflexão sobre a teoria e a prática inovadora em suas aulas. 
Nesse contexto, como afirma Moran, "Metodologias ativas são estratégias de ensino centradas na participação efetiva dos estudantes na construção do processo de aprendizagem, de forma flexível, interligada e híbrida" (Moran, 2018, p.4).

\section{MÉTODOS}

Em relação à metodologia, apresenta-se experiência com a formação continuada proposta pelas autoras que desencadeou também a pesquisa que está caracterizada de acordo com a abordagem, como qualitativa, cuja razão principal está em entender, compreender as questões que norteiam esse processo.

De acordo com Gerhardt e Silveira (2009, p. 31), a pesquisa qualitativa não se preocupa com representatividade numérica, mas, sim, com 0 aprofundamento da compreensão de um grupo social, de uma organização. Também aplicada no sentido de produzir conhecimentos com aplicação prática, buscando compreender a formação continuada como uma questão a ser priorizada na aquisição de conhecimentos pelos educadores. A pesquisa bibliográfica entra neste trabalho a partir dos conceitos trabalhados $\mathrm{e}$ fundamentados em autores que embasam as tecnologias educacionais.

Para Freire (1996, p. 14),

[...] Não há ensino sem pesquisa e pesquisa sem ensino. Esses que fazeres se encontram um no corpo do outro. Enquanto ensino continuo buscando, reprocurando. Ensino porque busco, porque indaguei, porque indago e me indago. Pesquiso para constatar, constatando, intervenho intervindo educo e me educo. Pesquiso para conhecer o que ainda não conheço e comunicar ou anunciar a novidade.

$\mathrm{Na}$ execução desta pesquisa aplicou-se a formação continuada com professores da Educação Infantil e Ensino Fundamental do município de Morro da Fumaça- SC ao logo de três meses, em encontros semanais perfazendo sessenta horas de estudo. No decorrer destes, foram utilizados textos, apresentações em PowerPoint sobre conceitos, com debates e trabalhos em grupo. Foram oportunizadas também atividades envolvendo as TICs, para compartilhar diversas experiências com vídeos, redes sociais, experimentos 
remotos, sites que divertem e educam e jogos sérios. A última etapa visou a construção e a aplicação de projetos colaborativos envolvendo as TICs.

De acordo com Gil, (2002, p.17) há diversas razões para realizar uma pesquisa, que podem decorrer da satisfação de conhecer ou fazer algo mais eficiente ou eficaz.

\section{RESULTADOS}

Os resultados desta pesquisa nos mostraram a carência dos educadores em estudos na área da tecnologia aplicada à sala de aula. As atividades desenvolvidas ao longo dos estudos na formação continuada resultaram na elaboração de projetos interdisciplinares, que foram aplicados com os alunos. Essas experiências foram socializadas, demonstrando o interesse e a participação dos educadores. A prática se fez a partir de estudos teóricos e enfatizaram a integração das TICs nos projetos que foram desenvolvidos. A articulação entre as áreas do conhecimento possibilitou trabalhos interdisciplinares, oportunizando o diálogo entre as diferentes visões sobre determinado tema.

Nesse sentido, a visão interdisciplinar ao longo da elaboração dos projetos envolvendo as TICs durante a formação continuada, permitiu aos educadores participantes um olhar mais amplo de sua área de conhecimento como também expandir para outras áreas, valorizando a contribuição de cada uma para o processo ensino-aprendizagem. As tecnologias na educação permitiram esse diálogo entre as áreas, assim como motivaram para a aprendizagem. Essa contribuição se percebe no interesse em assistir um vídeo, comunicar-se com alguém em tempo real, utilizar jogos em diferentes contextos, produzir um livro virtual etc.

O conhecimento das metodologias ativas e o que fazer com as tecnologias foi eficaz a esses educadores, no sentido de perceber quais atividades de aprendizagem podem se aliar às tecnologias com sucesso.

Dentre os projetos produzidos durante a formação, selecionamos alguns, mencionados a seguir. 
O projeto "O Meio Ambiente pede ajuda: e agora quem poderá nos defender?", desenvolvido para alunos da Educação Infantil, contou com apresentação de filmes e vídeos e sobre o tema. Culminou em um concurso de desenhos sobre o meio ambiente nas redes sociais (Facebook).

O projeto "Ditados populares" envolveu alunos dos anos iniciais, com o objetivo de reconhecer ditados populares, através de pesquisas na internet. $O$ projeto envolveu a criação dos ditados populares nos smartphones, com emojis do WhatsApp. Decifrar os ditados construídos foi o momento de interação e diversão do grupo de alunos participantes.

O projeto "Criando e-mails: formas de comunicação virtual" teve como público-alvo os alunos do $3^{\circ}$ ano do Ensino Fundamental e oportunizou a criação de e-mails para todos os alunos. Como atividade principal, os alunos produziram situações problemas envolvendo cálculos matemáticos e os enviaram aos colegas para os mesmos resolverem.

O projeto "Viagem virtual ao museu do Louvre" teve como objetivos aproximar os alunos do mundo virtual, promover o conhecimento de um museu e aliar a história às tecnologias. Os alunos do $7^{\circ}$ ano do Ensino Fundamental, ao estudar o conteúdo Renascimento, tiveram a oportunidade de fazer um tour virtual dentro do museu do Louvre para conhecer as obras renascentistas. Como atividade complementar cada aluno fez a escolha de uma obra de arte e desenvolveu uma releitura.

O projeto "Redes sociais: riscos e benefícios" oportunizou aos alunos do 6o ao 9o ano do Ensino Fundamental debater sobre pontos positivos e negativos da internet. Como atividades principais, pesquisaram postagens sobre preconceito, apresentando os prints e argumentando sobre o tema. Como culminância do projeto, criaram a cartilha online "Navegar com segurança".

Em todos os projetos apresentados, os grupos foram formados por educadores das diferentes áreas do conhecimento, reforçando assim a interdisciplinaridade inerente às TICs.

As atividades envolveram as tecnologias e evidenciaram a relevância de formar o educador nesse contexto. As opções de uso das tecnologias são 
muito variadas e, como se pode perceber, há em qualquer área do conhecimento uma abertura para estas atividades.

Os relatos dos professores participantes na formação continuada demonstraram que 0 uso das tecnologias nas aulas contribuiu significativamente, tornando-as mais produtivas e criativas. Houve maior interação e interesse nas aulas, proporcionado melhorias na aprendizagem de alguns conteúdos, que antes eram trabalhados de forma tradicional com o uso do livro didático e caderno. Os professores vislumbraram uma transformação do agir pedagógico utilizando as TICs. A percepção da importância do uso, a vivência de atividades práticas aliadas aos estudos teóricos e a troca de experiências com outros educadores, produziram um efeito motivador.

Quando questionados sobre as mudanças na prática pedagógica a partir da formação continuada, os educadores reafirmaram a importância destes momentos de estudo. Em entrevista com os professores participantes, notou-se o quanto a formação contribuiu para ampliar seus conhecimentos acerca das TICs na sala de aula. Os mesmos relataram que conseguiram ver, nas tecnologias, um apoio a determinados conteúdos.

Havia insegurança por parte de alguns educadores da Educação Infantil, pois não costumavam usas as tecnologias, porém, a partir da formação, realizaram um projeto sobre alimentação saudável com atividades online.

Por outro lado, os educadores concluíram que falta infraestrutura em muitas escolas, como internet mais rápida e equipamentos. Perceberam, contudo, que há outras formas de utilizar as TICs na sala de aula e também fora dela. Iniciaram passos na construção de uma sala de aula invertida., que se caracteriza, pela apresentação de conteúdos através de vídeos, sites de pesquisa e outros recursos tecnológicos, antes de serem debatidos em sala de aula. Criando outros ambientes de aprendizagem através do uso das TICs. (BERGMANN, 2016)

Por fim, os educadores em geral demonstraram que a socialização dos projetos foi a culminância da formação continuada. Houve uma variedade de situações de aprendizagem apresentadas pelos participantes nas quais a tecnologia se fez presente e os motivou ir em busca de atividades inovadoras com a integração das TICs, sem deixar de trabalhar os conteúdos curriculares.

Criar Educação, Criciúma, v. 8, no1, jan/jul 2019.- PPGE - UNESC 


\section{CONSIDERAÇÕES FINAIS}

A formação continuada dos professores foium desafio solucionável para o desenvolvimento e a adoção das TICs no contexto escolar. Promover o acesso à formação continuada dos educadores se faz urgente e necessário. Há uma lacuna entre as TICs e o trabalho docente, que precisa ser revista como prioridade. A aproximação dos educadores participantes da formação com as tecnologias fez a diferença no processo de ensino-aprendizagem.

Nesse sentido, percebe-se o quanto foram válidos e consistentes os momentos de estudo. A partir da teoria elaborou-se a prática; uma fundamentou e complementou a outra.

Foi de fundamental importância desenvolver, ao longo da formação continuada, os projetos envolvendo as TICs, mostrando na prática ações educativas que foram otimizadas com as tecnologias.

Deste modo, percebe-se a relevância desse trabalho no sentido de trazer uma reflexão: os professores necessitam aprender sobre tecnologias educacionais.

Precisam não somente ter acesso aos recursos tecnológicos, mas desenvolver habilidades e competências para fazer uso deles, impactando efetivamente o trabalho em sala de aula e trazendo um novo paradigma de educação.

\section{REFERÊNCIAS}

BACICH, L.; MORAN. J. (Org.). Metodologias ativas para uma educação inovadora: uma abordagem téorico-prática. Porto Alegre: Penso, 2018.

BARRAGÁN, A. G. C. Construyendoeltercerespacioenlaformación inicial delprofesorado: Una experienciapráctica desde el enfoque de losfondosdigitales de conocimiento e identidad. Relatec: Revista Latinoamericana de Tecnología Educativa, San Sebastian, v. 16, p.35-49, 2017. Disponível em: <http://relatec.unex.es/article/view/2966/2008>. Acesso em: 17 abr. 2018. 
BEHAR, Patricia A;OL. (orgs). Modelos Pedagógicos em Educação à distância. Porto Alegre: Artmed, 2009.

BERGMANN, J.; SAMS, A. Sala de aula invertida: uma metodologia ativa de aprendizagem. Rio de Janeiro: LTC, 2016.

COSTA, Fernando Albuquerque et al. Repensar as TIC na Educação: $O$ professor como agente transformador. Carnaxide:Santillana, 2012.

FERRARI; SOTERO. A educação na cultura digital. São José: Ilha Mágica, 2017.

FREIRE, Paulo. Pedagogia da Autonomia: saberes necessários à prática educativa. São Paulo: Paz e Terra, 1996.

GERHARDT, Tatiana Engel; SILVEIRA,DeniseTolfo (Orgs). Métodos de pesquisa. Porto Alegre: Editora da UFRGS, 2009.

GIL, Antônio Carlos. Como elaborar projetos de pesquisa. 4. ed. São Paulo: Atlas, 2002.

MOLIN, S. L.; RAABE, A. L. A. Novas tecnologias na educação: transformações da prática pedagógica no discurso do professor. Acta Scientiarum. Education, Maringá, v. 34, n. 2, p. 249-259, nov. 2012. Disponível em: <http://periodicos.uem.br/ojs/index.php/ActaSciEduc/article/view/16485/9989>. Acesso em: 15 abr. 2018.

NEW MEDIA CONSORTIUM. The NMC Horizon Report: Educação Básica Edição 2015. NMC, 2015. Produzido em conjunto com New Media Consortium (NMC) e o Consortium ofSchool Networking (CoSN).

SOUSA, Robson Pequeno de; MOITA, Filomena da M. C da S. C.; CARVALHO, Ana Beatriz Gomes (Orgs). Tecnologias digitais na educação. Campina Grande: EDUEPB, 2011.

BERGMANN, J.; SAMS, A. Sala de aula invertida: uma metodologia ativa de aprendizagem. Rio de Janeiro: LTC, 2016.

Recebido em dezembro 2018

Aprovado em março 2019 